\title{
Effects of Age and Stand Density of Mother Trees on Early Pinus thunbergii Seedling Establishment in the Coastal Zone, China
}

\author{
Peili Mao, ${ }^{1}$ Guangxuan Han, ${ }^{1}$ Guangmei Wang, ${ }^{1}$ Junbao Yu, ${ }^{1}$ and Hongbo Shao ${ }^{1,2}$ \\ ${ }^{1}$ Key Laboratory of Coastal Zone Environmental Processes, Yantai Institute of Coastal Zone Research (YIC), \\ Chinese Academy of Sciences (CAS), Yantai 264003, China \\ ${ }^{2}$ Institute of Life Sciences, Qingdao University of Science \& Technology, Qingdao 266042, China
}

Correspondence should be addressed to Junbao Yu; jbyu@yic.ac.cn and Hongbo Shao; shaohongbochu@126.com

Received 17 April 2014; Revised 27 April 2014; Accepted 30 April 2014; Published 15 May 2014

Academic Editor: Xu Gang

Copyright (c) 2014 Peili Mao et al. This is an open access article distributed under the Creative Commons Attribution License, which permits unrestricted use, distribution, and reproduction in any medium, provided the original work is properly cited.

\begin{abstract}
Effects of age and stand density of mother tree on seed germination, seedling biomass allocation, and seedling growth of Pinus thunbergii were studied. The results showed that age of mother tree did not have significant influences on seed germination, but it was significant on seedling biomass allocation and growth. Seedlings from the minimum and maximum age of mother tree had higher leaf mass ratio and lower root mass ratio than from the middle age of mother tree. Moreover, they also had higher relative height growth rate and slenderness, which were related to their biomass allocation. Stand density of mother tree mainly demonstrated significant effects on seed germination and seedling growth. Seed from higher stand density of mother tree did not decrease germination rate, but had higher mean germination time, indicating that it delayed germination process. Seedlings of higher stand density of mother tree showed higher relative height growth rate and slenderness. These traits of offspring from higher stand density of mother tree were similar to its mother, indicating significant environmental maternal effects. So, mother tree identity of maternal age and environments had important effects on natural regeneration of the coastal $P$. thunbergii forest.
\end{abstract}

\section{Introduction}

Plant regeneration is one of the problems in the ecological field in recent decades $[1,2]$. The main regeneration stages of seed plants involve seed production, dispersal, and seedling establishment $[1,2]$. Seed production is the first stage of plant regeneration. Seed quality and quantity are affected by maternal identity [3-7], such as maternal age $[8,9]$ and maternal environment $[10,11]$, which will influence the natural regeneration processes.

Mother tree age has significant effect on seed production. With the increase of age, Cistus albidus showed the highest fecundity at the middle age [9]. The seed production of Picea mariana [12] and Pinus sylvestris [13] increased steadily with mother tree age. Seed quality is affected significantly by tree age, too. Some tree species exhibited the highest seed germination rate in the middle age, such as Sorbus torminalis [14] and Pinus echinata [15]. Pinus pinea increased seed vigour with the increase of mother tree age [10]. Pinus pinaster increased seed germination time with increasing mother tree age [16]. However, Connor and Lanner [17] did not identify any relationship between tree age and pollen viability, seed weight, seed germination, and seedling biomass in Pinus longaeva. Müller et al. [9] also found that C. albidus did not decline in seed viability with increasing tree age. So, the relationship between tree age and seed production is ambiguous.

Maternal environmental effects enhance transgenerational plasticity in the maternal environment $[18,19]$, which have attracted considerable attentions in recent years [2022]. As sessile organisms, the seed dispersal range of plant is often limited, with most seeds falling to the growth conditions of parents [23]. Parents' experiences from different abiotic stresses can preadapt offspring for functioning under the same stresses, which improves offspring fitness [21]. The maternal environment affects traits like seed traits [21,24], germination $[3,18]$, seedling performance $[5,19,21]$, and biotic stress $[25,26]$. Environmental maternal effects can be inherited to the next generation and persist at least one generation [20, 21]. Moreover, Herman et al. [21] found 
TABle 1: Mother tree characteristics of Pinus thunbergii for collecting cones and seeds.

\begin{tabular}{lcccc}
\hline \multirow{2}{*}{ Age class } & \multicolumn{2}{c}{ D I } & & D II \\
& Diameter at breast height $(\mathrm{cm})$ & Height of mother tree $(\mathrm{m})$ & Diameter at breast height $(\mathrm{cm})$ & Height of mother tree $(\mathrm{m})$ \\
\hline M I & $9.55 \sim 12.74$ & $6.1 \sim 7.3$ & $6.37 \sim 9.55$ & $5.6 \sim 6.4$ \\
M II & $12.89 \sim 15.92$ & $6.5 \sim 9.2$ & $10.51 \sim 12.74$ & $6.4 \sim 8.6$ \\
M III & $16.56 \sim 19.11$ & $6.8 \sim 9.8$ & $12.89 \sim 15.92$ & $6.3 \sim 8.6$ \\
\hline
\end{tabular}

that transgenerational environmental effects were cumulative over the course of two successive generations in Polygonum persicaria. The inherited adaptations did not change the DNA sequence but regulated gene expression [27]. Despite the substantial variation in transgenerational responses to stress observed, the molecular mechanism of environmental maternal effects remains poorly understood [22].

Coastal forests play a significant protective function in reducing natural disasters in the coastal zone [28, 29]. Pinus thunbergii is one of the most important tree species in coastal forests of the Japanese islands and Shandong Province, China [30]. Because $P$. thunbergii forest near the sea is vulnerable to wind risk, few thinnings are carried out for their regeneration $[29,31,32]$. Due to few thinnings which lead to high stand density and low light intensity in the forest, the natural regeneration of the light demanding species $P$. thunbergii becomes very difficult [29-31]. Litter demonstrates negative effects on the regeneration $[30,31]$, which was similar to $P$. pinea natural regeneration [33]. Grass cover did not affect the survival and growth of the seedlings [30]. Grainger and Van Aarde $[34,35]$ thought the management of coastal forest restoration should be based on succession theory. However, the effect of seed production of $P$. thunbergii on its natural regeneration has not been researched systematically. So, we studied the influence of the mother tree age, the maternal environment, and their interaction, providing a quantification of the relative contribution of age and epigenetic effects on both the seed germination and the seedling growth.

\section{Materials and Methods}

2.1. Study Area and Species. The study was carried out at the coastal $P$. thunbergii forest around CAS Experimental Station of Integrated Coastal Environment in Muping, China $\left(37^{\circ} 27^{\prime} 15^{\prime \prime} \mathrm{N}, 121^{\circ} 41^{\prime} 57^{\prime \prime} \mathrm{E}\right)$. It is a warm temperate continental monsoon climate in East Asia. The annual rainfall is $760 \mathrm{~mm}$, and the mean annual temperature is $11.5^{\circ} \mathrm{C}$. It is coastal sandy soil, whose soil organic matter content is less than 1\%. P. thunbergii forest was planted in the 1950 s and almost was pure. Understory vegetation was simple. Shrub species mainly consisted of Amorpha fruticosa, Vitex trifolia Linn.var. simplicifolia Cham., Lespedeza bicolor, and Rosa multiflora. Grass species is made of Carex rigescens, Corispermum stenolepis, Salsola ruthenica lljin var. ruthenica, Imperata cylindrica var. major, Portulaca oleracea, Calystegia soldanella, Ischaemum antephoroides, Artemisia capillaris Thunb., Commelina communis, Atriplex sibirica, and Solanum nigrum.
2.2. Cone and Seed Collection. Collection of the cones was carried out in late September of the year 2008. According to the census results of the community structure of the coastal P. thunbergii forest in 2007, we collected cones of different mother tree age classes (delegated by diameters at breast height) from a low (1600-1900 N/ha, D I) and a high (1600-1900 N/ha, D II) stand density, respectively (Table 1). We selected 10 15 individuals in each mother age class. More than 5 cones were randomly collected from each mother tree. Cones were air dried for several months until almost opened. Then, we selected filled seeds to use in the experiment.

2.3. Effect of Age and Stand Density of Mother Tree on Seed Germination. On 4 December 2009, 20 filled seeds of each pot were sowed in plastic pots of $0.2 \mathrm{~m}$ height and $0.22 \mathrm{~cm}$ diameter. The pots were filled with sand taken from the forest of cone collection and sieved to remove debris and seeds. Each treatment was determined by the age and stand density of mother tree (Table 1). Each treatment had five replicates. This experiment was conducted at the nurse garden of forestry bureau of Laishan District in Yantai, Shandong Provinces, China. The pots were laid randomly inside a low plastic tunnel. During the seed germination period, the minimal and maximum temperature in the tunnel varied from $-6^{\circ} \mathrm{C}$ to $34^{\circ} \mathrm{C}$. All pots were well watered to keep the soil near field capacity. After germinated seed was found on March 15, 2010, germination was assessed every day until April 28, 2010. Then, we evaluated germination rate $\left(G_{r}, \%\right)$ and mean germination time (MGT, d). $G_{r}$ was calculated as the ratio between the number of germinated seeds at a given time and the number of seeds sown. MGT was calculated as follows [36]: $\mathrm{MGT}=\left(N_{1} T_{1}+N_{2} T_{2}+\cdots+N_{x} T_{x}\right) /$ total number of seeds germinated, where $N_{i}=$ number of seeds germinating within consecutive intervals of time and $T_{i}=$ the time between the beginning of the test and the end of the particular interval of measurement.

After the experiment end, five seedlings of each pot were removed from the pots and washed free of sand. Each seedling was divided into leaf, stem, and root, putted into a paper bag, and dried at 75 for $48 \mathrm{~h}$. The masses of leaf, stem, and root were weighed by and electronic balance $(0.1 \mathrm{mg}$ accuracy). Individual seedling biomass (leaf + stem + root mass, g), leaf mass ratio (LMR, leaf mass/seedling biomass, $\mathrm{g} \cdot \mathrm{g}^{-1}$ ), stem mass ratio (SMR, stem mass/seedling biomass, $\left.\mathrm{g} \cdot \mathrm{g}^{-1}\right)$, and root mass ratio (RMR, root mass/seedling biomass, $g \cdot g^{-1}$ ) were accounted.

2.4. Effect of Age and Stand Density of Mother Tree on Seedling Growth. Three light levels were created by covering the low 
TABLE 2: Two-way ANOVA analyses of effects of age and stand density of mother tree age and their interaction on seed germination and seedling biomass allocation for Pinus thunbergii.

\begin{tabular}{lccccc}
\hline & \multicolumn{2}{c}{ Age } & \multicolumn{2}{c}{ Density } & \multicolumn{2}{c}{ Age $\times$ Density } \\
& $F$ value & $P$ value & $F$ value & $P$ value & $F$ value \\
\hline Germination rate (Gr) & 0.49 & $P=0.62$ & 1.27 & $P=0.27$ & 0.44 \\
Mean germination time (MGT) & 0.96 & $P=0.40$ & 9.45 & $P<0.01$ & 0.66 \\
Individual biomass & 1.33 & $P=0.28$ & 3.93 & $P=0.06$ & 0.06 \\
Leaf mass ratio (LMR) & 5.44 & $P<0.05$ & 6.89 & $P<0.05$ & 6.79 \\
Stem mass ratio (SMR) & 1.06 & $P=0.36$ & 2.28 & $P=0.15$ & 0.96 \\
Root mass ratio (RMR) & 6.38 & $P<0.01$ & 1.94 & $P=0.18$ & 4.35 \\
\hline
\end{tabular}

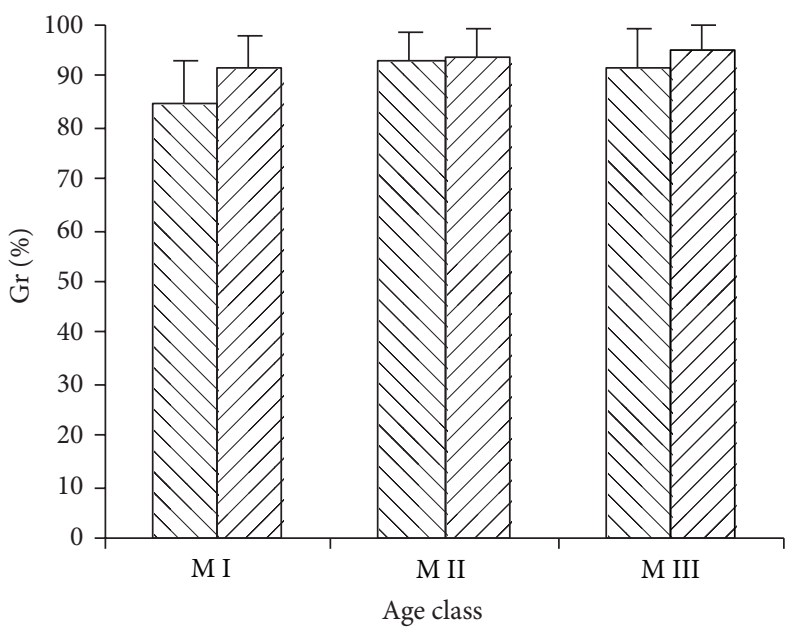

$\square \mathrm{DI}$

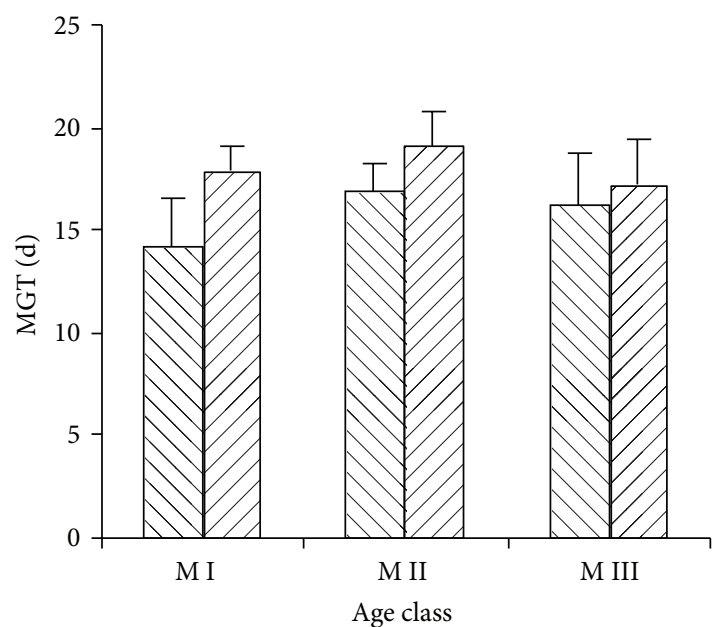

$\square \mathrm{DI}$

$\nabla$ D II

(a)

(b)

FIGURE 1: Effects of age and stand density of mother tree on seed germination.

tunnel with layers of black nylon cloths that had little effect on radiation quality [37]. The light levels in different treatments were $50 \%, 30 \%$, and $10 \%$ of the full light, respectively. Nine individuals of each pot leaved in the leaved seedlings of seed germination were transplanted into three pots on May 1, 2010 and each pot included three seedlings. Each pot was deposited randomly in different light levels, respectively. The growth experiment ended on December 30, 2010. During the experiment, seedling height and ground diameter were measured every month. We accounted relative height growth rate $\left(\mathrm{RGR}_{H},\left(\ln H_{2}-5 \ln H_{1}\right) /\left(T_{2}-T_{1}\right), \mathrm{cm} \cdot \mathrm{g}^{-1} \cdot \mathrm{d}^{-1}\right)$ and relative ground diameter growth rate $\left(\mathrm{RGR}_{D},\left(\ln D_{2}-\ln D_{1}\right) /\left(T_{2}-T_{1}\right)\right.$, $\left.\mathrm{mm} \cdot \mathrm{g}^{-1} \cdot \mathrm{d}^{-1}\right) . H$ is seedling height $(\mathrm{cm})$ and $D$ is seedling ground diameter $(\mathrm{cm})$. Subscripts refer to initial (1) or final (2) harvest. The slenderness was calculated according to Valladares et al. [38] by the following formula: slenderness = plant height/stem diameter.

2.5. Data Analysis. Seed germination responses were tested by using a two-way ANOVA, with age and stand density of mother tree as the source of variables. Three-way analysis of variance (ANOVA) was used to examine the main effects of light level, age, and stand density of mother tree and their interaction on seedling growth. Least-significant difference (LSD) multiple comparisons were conducted when there were significant differences. The statistically significant level was set at $P<0.05$. All statistics were conducted with SPSS for Windows 13.0 (SPSS, Chicago, IL, USA).

\section{Results}

3.1. Seed Germination. Both age and stand density of mother tree did not show significant effects on $G_{r}$ (Table 2; Figure 1). On MGT, age of mother tree had no significant effect, whereas stand density of mother tree exhibited significant effect. This result suggested that stand density of mother tree delayed germination time without changing seed quality.

3.2. Biomass Allocation. There were no significant differences on individual biomass both for age and for stand density of mother tree (Table 2, Figure 2). However, they showed different functions on biomass allocation. Age of mother tree showed significant effects on LMR and RMR but not on SMR. MI was similar to M III on $\operatorname{LMR}(P=0.51)$ and RMR 


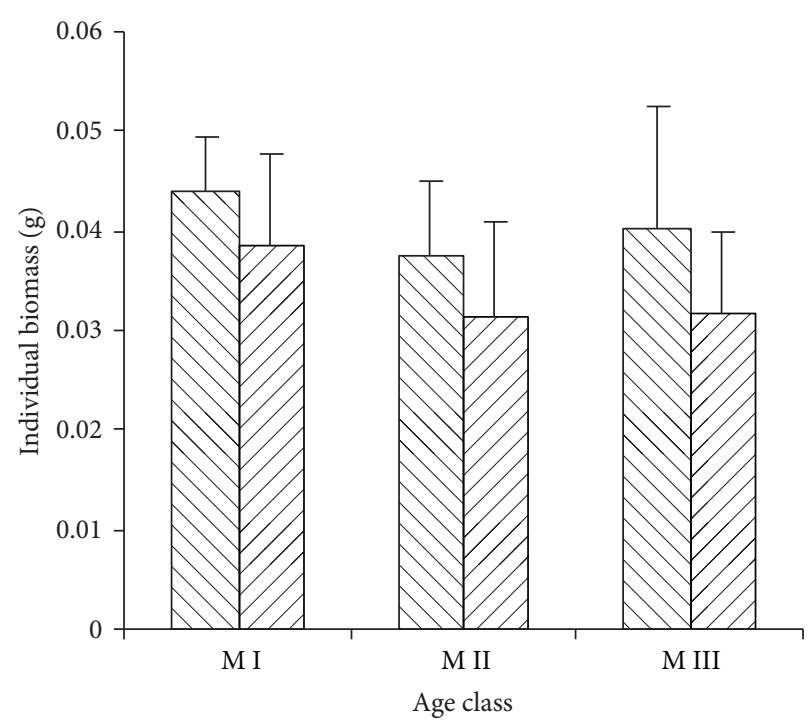

(a)

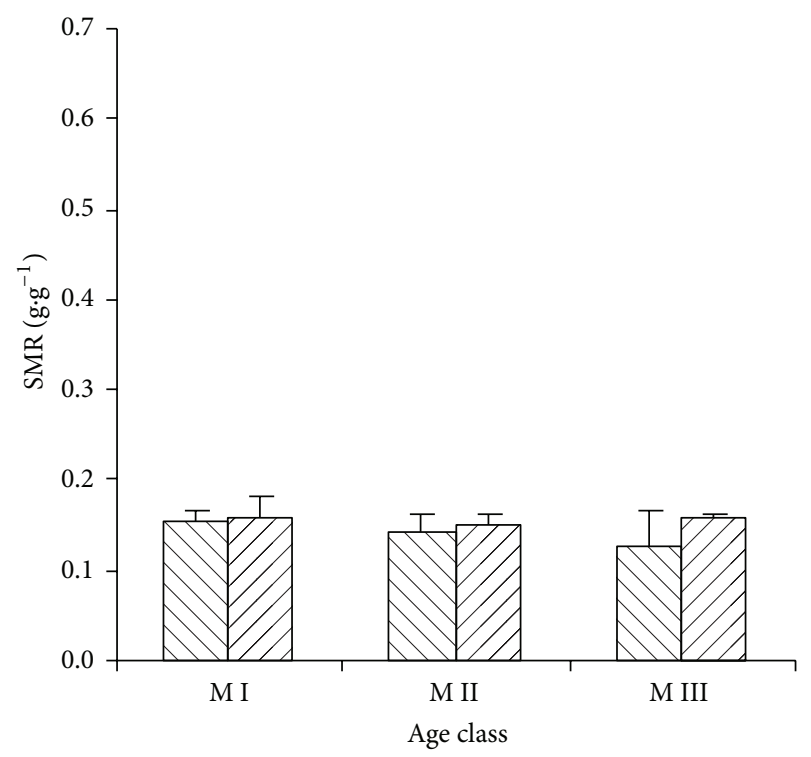

$\square \mathrm{DI}$

$\nabla$ D II

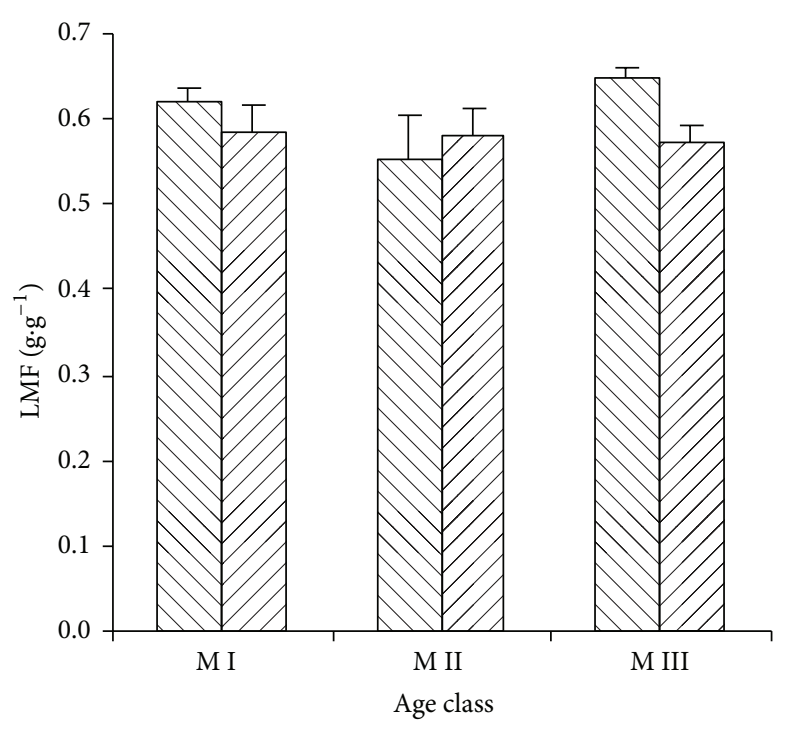

(b)

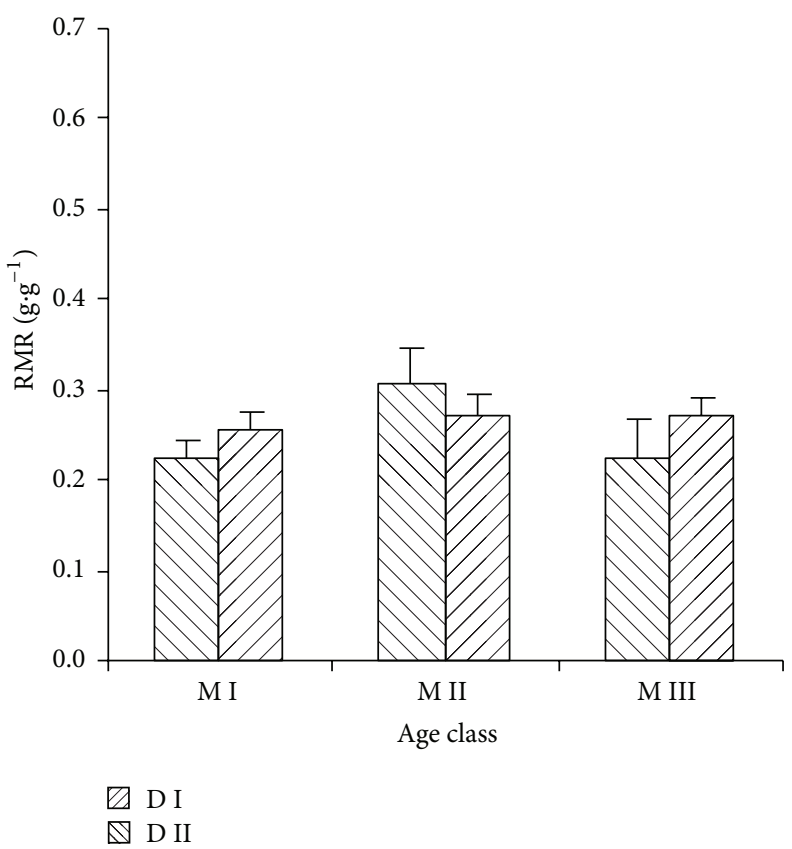

(d)

FIGURE 2: Effects of age and stand density of mother tree on seeding biomass allocation.

$(P=0.61)$. They were higher than M II on $\operatorname{LMR}(P<0.05)$, but lower than M II on RMR $(P<0.01)$. Stand density of mother tree only exhibited significant effect on LMR. D I showed higher LMR than D II.

3.3. Seedling Growth. Light intensity had significant effects on $\mathrm{RGR}_{H}$ and $\mathrm{RGR}_{D}$ (Table 3, Figure 3). There were no significant differences on $\mathrm{RGR}_{H}(P=0.93)$ and $\mathrm{RGR}_{D}$ $(P=0.19)$ between in $50 \%$ and $25 \%$ full light. However, they were lower on $\mathrm{RGR}_{H}(P<0.01)$ and higher on $\mathrm{RGR}_{D}$ $(P<0.01)$ than in $5 \%$ full light. These results suggested that $P$. thunbergii was a light demanding species. Age of mother tree had significant effects on $\mathrm{RGR}_{H}$ not on $\mathrm{RGR}_{D}$. M I was similar to M II $(P=0.21)$ and M III $(P=0.11)$ on $\operatorname{RGR}_{H}$, while M II was lower than M III $(P<0.01)$. Stand density of mother tree also had significant effects on $\mathrm{RGR}_{H}$ not on $\mathrm{RGR}_{D}$. D I had higher RGR $\mathrm{R}_{H}$ than D II in each light level.

Light intensity had significant effects on slenderness (Table 3, Figure 4). There was no significant difference on slenderness between in $50 \%$ and $25 \%$ full light $(P=0.14)$, while they were lower than in $5 \%$ full light $(P<0.05)$. Age of mother tree showed significant effects on slenderness. M I was similar to M III on slenderness $(P=0.36)$, whereas they were higher than M II $(P<0.01)$. Stand density of mother 
TABle 3: Three-way ANOVA analyses of effects of light level, age, and stand density of mother tree age and their interactions on seedling growth for Pinus thunbergii.

\begin{tabular}{|c|c|c|c|c|c|c|}
\hline \multirow{2}{*}{ Source } & \multicolumn{2}{|c|}{$\mathrm{RGR}_{H}$} & \multicolumn{2}{|c|}{$\mathrm{RGR}_{D}$} & \multicolumn{2}{|c|}{ Slenderness } \\
\hline & $F$ value & $P$ value & $F$ value & $P$ value & $F$ value & $P$ value \\
\hline Light & 8.60 & $P<0.01$ & 38.30 & $P<0.01$ & 41.20 & $P<0.01$ \\
\hline Age & 4.69 & $P<0.05$ & 1.49 & $P=0.23$ & 5.72 & $P<0.01$ \\
\hline Density & 4.98 & $P<0.05$ & 0.31 & $P=0.58$ & 19.53 & $P<0.01$ \\
\hline Light $\times$ age & 2.24 & $P=0.08$ & 6.27 & $P<0.01$ & 3.14 & $P<0.05$ \\
\hline Light $\times$ density & 0.47 & $P=0.63$ & 0.39 & $P=0.68$ & 4.36 & $P<0.05$ \\
\hline Age $\times$ density & 1.73 & $P=0.19$ & 1.24 & $P=0.30$ & 0.63 & $P=0.53$ \\
\hline Light $\times$ age $\times$ density & 1.30 & $P=0.28$ & 0.16 & $P=0.96$ & 2.01 & $P=0.11$ \\
\hline
\end{tabular}
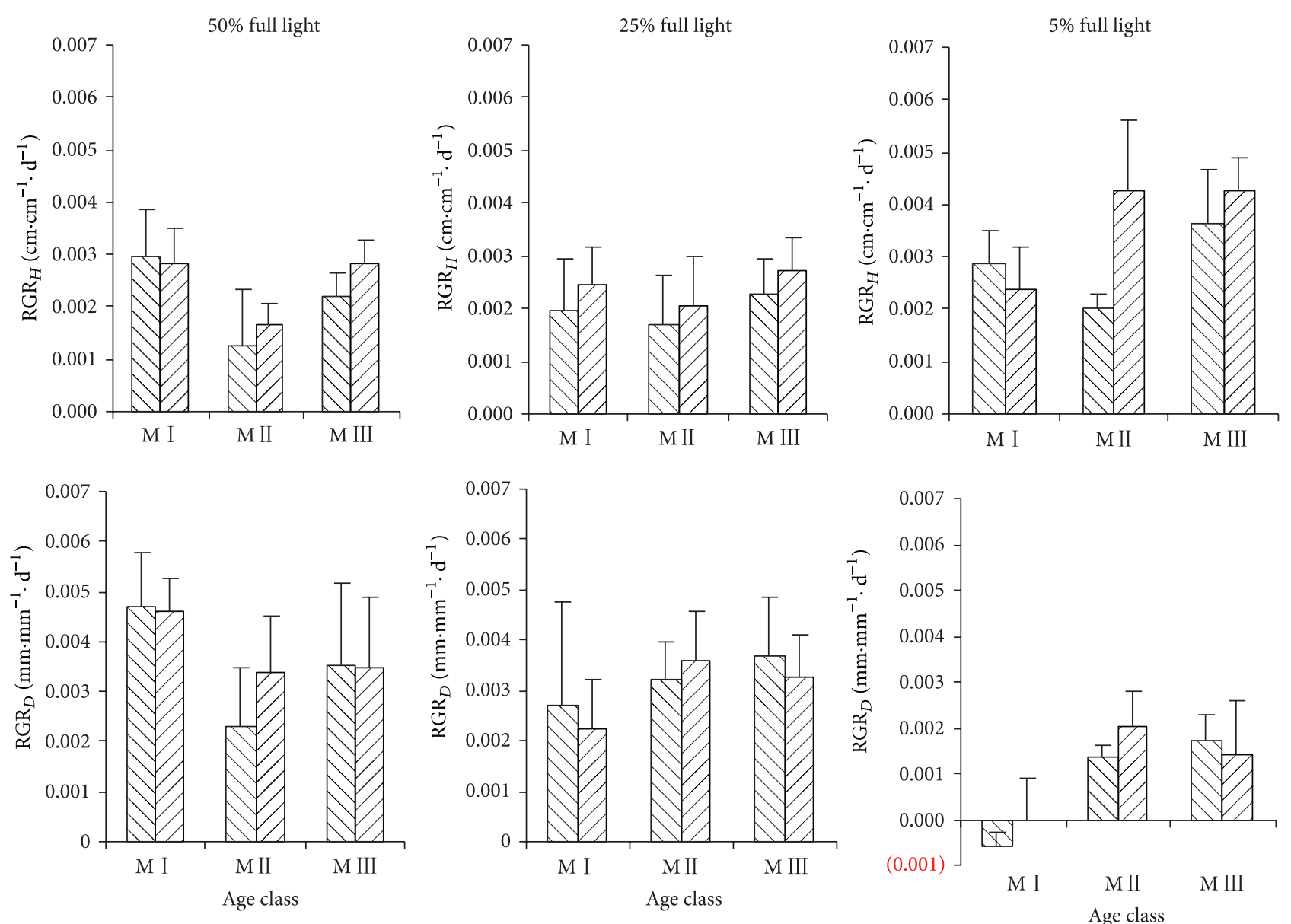

$\square$ D I
$\square$ D II

$\square$ D I
$\square$ D II

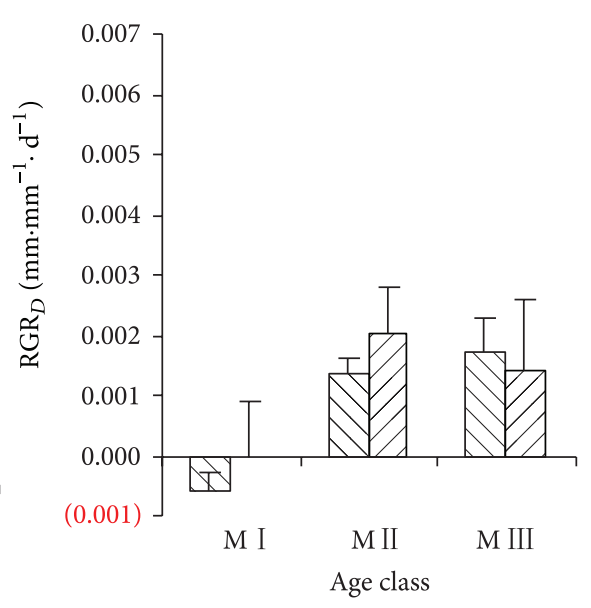

FIGURE 3: Effects of age and stand density of mother tree on seedling growth.

tree also had significant effect on slenderness. D I showed higher slenderness than D II in all light levels.

\section{Discussion}

In this paper, we found that both tree age and maternal environment of $P$. thunbergii mother tree influenced the trait expression of its offspring. However, they showed differently functional manners in seed germination, seedling biomass allocation, and seedling growth, which suggested that mother tree character on their offspring showed complex impacts.

Seed germination is vital for the establishment of plant individual, especially in unfavorable environments $[3,22]$. In this paper, we did not find significant effects of tree age on seed germination, which was in accord with Connor and Lanner [17] and Müller et al. [9]. Old C. albidus individuals 


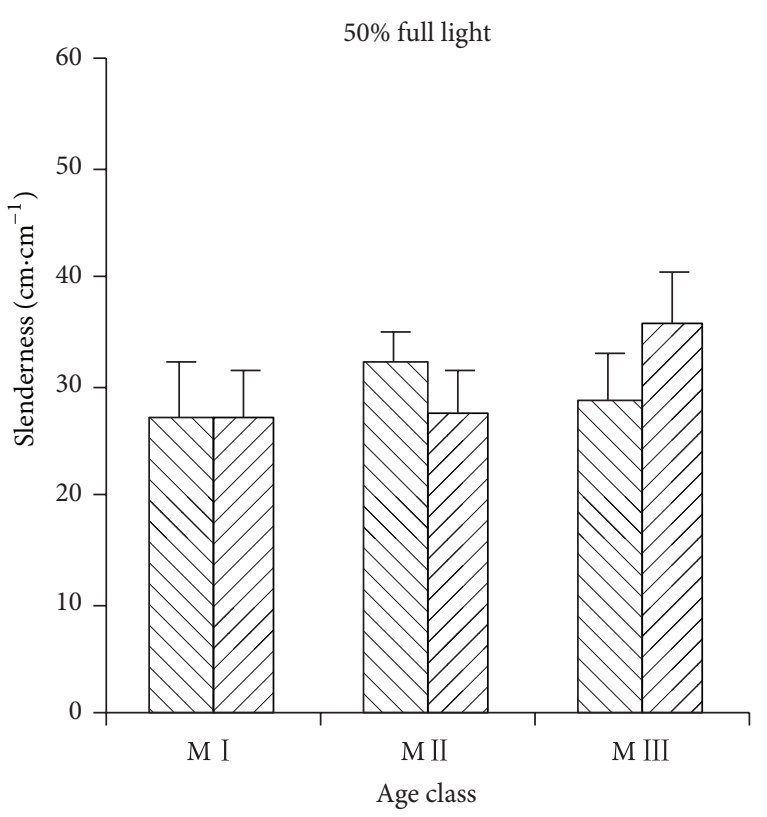

(a)

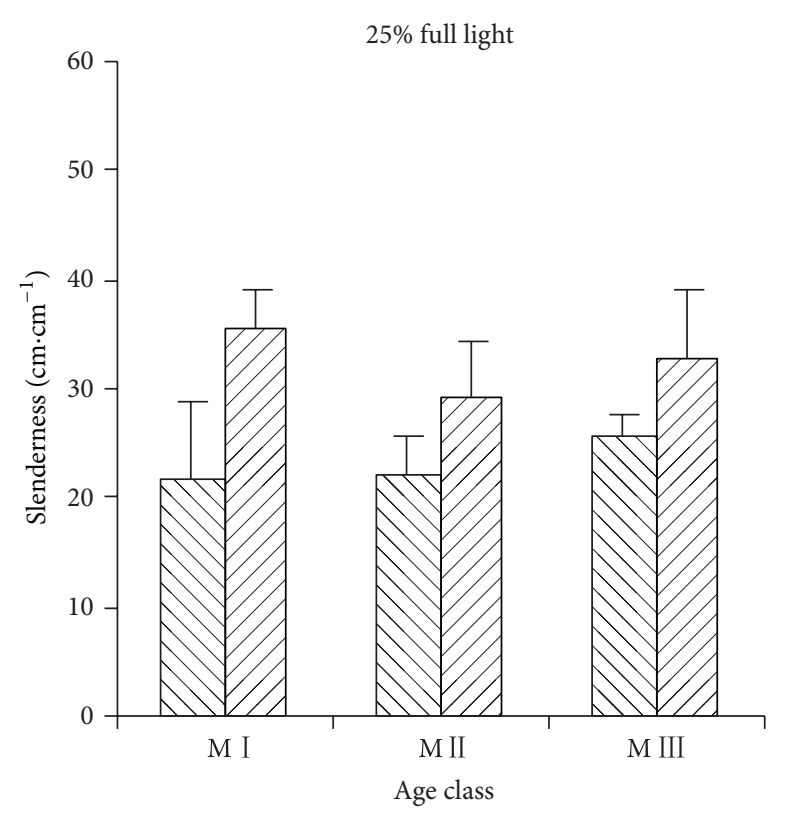

(b)

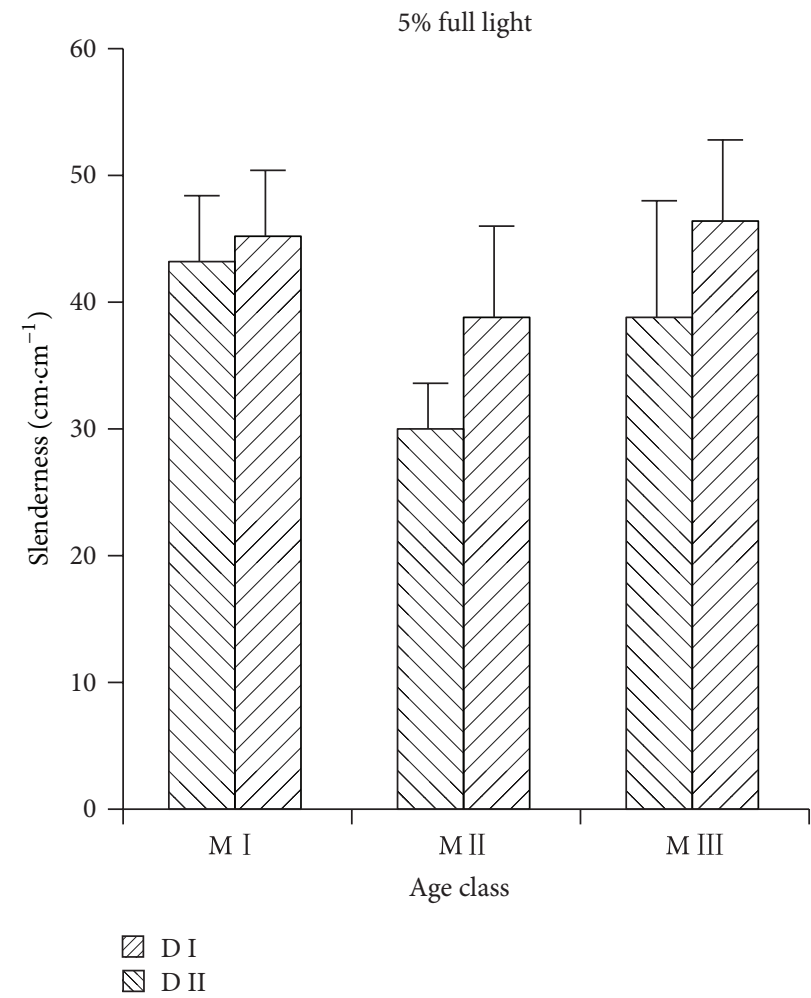

(c)

FIGURE 4: Effects of age and stand density of mother tree on seedling slenderness.

kept high seed quality in harsh environmental conditions by decreasing their growth and photosynthetic biomass [9]. However, S. torminalis [14] and P. echinata [15] had the highest germination rate in the middle age of mother tree. Old mother tree of $P$. pinea showed higher germination rate than the younger [10]. Higher stand density of mother tree did not decrease germination rate but delayed germination time. In the P. thunbergii coastal forest, higher stand density had deeper litter and lower soil moisture [30,31]. So, delay in the germination time of $P$. thunbergii in higher stand density was an adaptive manner in maternal environment. Similarly, seeds of $P$. pinaster from mother trees grown in the colder 
environment germinated 7.5 days later, which could help the offspring to escape from late frost damage [3]. Campanulastrum americanum seed showed greater germination rate in their maternal light environment, which was an important adaptive mode to improve fitness for their offspring $[18,19]$.

Biomass allocation adjusting is an important adaptive mode for plant species to survive in different environmental conditions [39]. Both age and stand density of mother tree did not show significant differences in the early seedling growth. However, they demonstrated different effects on seedling biomass allocation, which would influence seedling establishment. Maternal age effect had significant influences on LMR and RMR not on SMR. MI and MIII showed higher LMR than MII. High investment in leaf biomass is advantageous for plant species to survive in low light environment by increasing light interception ability [39] and keeping high photosynthetic capacity $[40,41]$. So, M I and M III would have higher growth rate in understory. M II had higher RMR, which improved water acquisition [21, 42]. So, M II will favor to survive in high light environment. Stand density of mother tree only influenced leaf mass ratio. D I had higher leaf mass ratio than D II, which seemed D II did not have growth advantage in understory. We thought this pattern would change with different environment conditions in its later growth process.

Growth integrates the effects of different stresses on plant species vigour and carbon balance [43]. With the decrease of light intensity, $P$. thunbergii seedling increased $\mathrm{RGR}_{H}$ and decreased $\mathrm{RGR}_{D}$, which confirmed it was a light demanding species [44]. Rapid height growth was advantageous for plant species to shade surrounding shorter plants and reach canopy [45]. Both age and stand density of mother tree showed significant effects on $\mathrm{RGR}_{H}$, suggesting height growth had vital function for the regeneration of $P$. thunbergii. M II exhibited the lowest $\mathrm{RGR}_{H}$, which was related to its lower leaf mass ratio $[46,47]$. D II had higher $\mathrm{RGR}_{H}$, especially in $25 \%$ and $5 \%$ full light, which was in accord with higher stand density of mother tree. Plant slenderness suggested its vigour [38]. Seedling under $5 \%$ full light had the highest slenderness, which indicated they were biomechanically weaker. Zhu et al. [30] found that all of the regenerated seedlings in the unthinned $P$. thunbergii stand were only 1-year-old. So, we thought low vigour of seedlings was an important reason for the failure of the establishment in understory. Higher slenderness for D II indicated that seedling was slimmer, which suggested significant environmental material effects.

\section{Conclusion}

Due to harsh physical environments in the coastal shore, natural regeneration for the coastal $P$. thunbergii forest is very difficult. Seed production is the first step of natural regenerationfor $P$. thunbergii. In this paper, we found that maternal identity had important role on their offspring' seed germination, seedling biomass allocation, and seedling growth. However, there were different functions between age and stand density of mother tree. The age of mother tree influenced seedling growth by altering their biomass allocation. The stand density of mother tree influenced seedling establishment by environmental maternal effects on seed germination and seedling growth. So, it is an important research to clarify more maternal environmental effects. Moreover, we should also consider maternal effects and physical environments and their interaction in order to elucidate natural regeneration mechanism of the coastal $P$. thunbergii forest.

\section{Conflict of Interests}

The authors declare that there is on conflict of interests regarding the publication of this paper.

\section{Acknowledgments}

This study was supported by Yantai City Science and Technology Support Program of China (2012017; 2011016), the National Basic Research Program of China (2013CB430403), the CAS/SAFEA International Partnership, Program for Creative Research Teams, One Hundred-Talent Plan of Chinese Academy of Sciences (CAS), the Chinese Academy of Sciences (CAS) Visiting Professorship for Senior International Scientists (2012T1Z0010), the Science \& Technology Development Plan of Shandong Province (2010GSF10208), Yantai Double-hundred High-end Talent Plan (XY-003-02), and 135 Development Plan of YIC-CAS.

\section{References}

[1] R. Nathan and H. C. Muller-Landau, "Spatial patterns of seed dispersal, their determinants and consequences for recruitment," Trends in Ecology and Evolution, vol. 15, no. 7, pp. 278285, 2000.

[2] J. S. Clark, B. Beckage, P. Camill et al., "Interpreting recruitment limitation in forests," American Journal of Botany, vol. 86, no. 1, pp. 1-16, 1999.

[3] C. Cendán, L. Sampedro, and R. Zas, “The maternal environment determines the timing of germination in Pinus pinaster," Environmental and Experimental Botany, vol. 94, pp. 66-72, 2013.

[4] A. Fabião, C. Faria, M. H. Almeida, and A. Fabião, "Influence of mother plant and scarification agents on seed germination rate and vigor in Retama sphaerocarpa L., (Boissier)," IForestBiogeosciences and Forestry, pp. e1-e7, 2014.

[5] V. González-Rodríguez, I. C. Barrio, and R. Villar, "Withinpopulation variability influences early seedling establishment in four Mediterranean oaks," Acta Oecologica, vol. 41, pp. 82-89, 2012.

[6] I. Stancic, J. Zivic, S. Petrovic, and D. Knezevic, "Impact of genes and proportional contribution of parental genotypes to inheritance of root yield and sugar content in diploid hybrids of sugar beet," The Scientific World Journal, vol. 2014, Article ID 580623, 5 pages, 2014.

[7] W. Fang, Z. Wang, R. Cui, J. Li, and Y. Li, "Maternal control of seed size by EOD3/CYP78A6 in Arabidopsis thaliana," The Plant Journal, vol. 70, pp. 929-939, 2012.

[8] G. Ne'Eman, S. Goubitz, M. J. A. Werger, and A. Shmida, "Relationships between tree size, crown shape, gender segregation 
and sex allocation in Pinus halepensis, a Mediterranean pine tree," Annals of Botany, vol. 108, no. 1, pp. 197-206, 2011.

[9] M. Müller, L. Siles, J. Cela, and S. Munné-Bosch, "Perennially young: seed production and quality in controlled and natural populations of Cistus albidus reveal compensatory mechanisms that prevent senescence in terms of seed yield and viability," Journal of Experimental Botany, vol. 65, pp. 287-297, 2014.

[10] P. Ganatsas, M. Tsakaldimi, and C. Thanos, "Seed and cone diversity and seed germination of Pinus pinea in Strofylia Site of the Natura 2000 Network," Biodiversity and Conservation, vol. 17, no. 10, pp. 2427-2439, 2008.

[11] P. H. S. Brancalion, A. D. L. C. Novembre, and R. R. Rodrigues, "Seed development, yield and quality of two palm species growing in different tropical forest types in SE Brazil: implications for ecological restoration," Seed Science and Technology, vol. 39, no. 2, pp. 412-424, 2011.

[12] J. N. Viglas, C. D. Brown, and J. F. Johnstone, "Age and size effects on seed productivity of northern black spruce," Canadian Journal of Forest Research, vol. 43, pp. 534-543, 2013.

[13] T. A. Mukassabi, A. Polwart, T. Coleshaw, and P. A. Thomas, "Scots pine seed dynamics on a waterlogged site," Trees, vol. 26, pp. 1305-1315, 2012.

[14] K. Espahbodi, S. M. Hosseini, H. Mirzaie-Nodoushan, M. Tabar, M. Akbarinia, and Y. Dehghan-Shooraki, "Tree age effects on seed germination in Sorbus torminalis," General and Applied Plant Physiology, vol. 33, pp. 107-119, 2007.

[15] K. J. Grayson, R. F. Wittwer, and M. G. Shelton, "Cone characteristics and seed quality 10 years after an uneven-aged regeneration cut in shortleaf pine stands," General Technical Reports SRS-48, Department of Agriculture, Forest Service, Southern Research Station, Asheville, NC, USA, 2002.

[16] R. Alvarez, L. Valbuena, and L. Calvo, "Influence of tree age on seed germination response to environmental factors and inhibitory substances in Pinus pinaster," International Journal of Wildland Fire, vol. 14, no. 3, pp. 277-284, 2005.

[17] K. F. Connor and R. M. Lanner, "Effects of tree age on pollen, seed, and seedling characteristics in Great Basin bristlecone pine," Botanical Gazette, vol. 152, no. 1, pp. 107-113, 1991.

[18] L. F. Galloway, "Maternal effects provide phenotypic adaptation to local environmental conditions," New Phytologist, vol. 166, no. 1, pp. 93-100, 2005.

[19] L. F. Galloway and J. R. Etterson, "Transgenerational plasticity is adaptive in the wild," Science, vol. 318, no. 5853, pp. 1134-1136, 2007.

[20] J. J. Herman and S. E. Sultan, "Adaptive transgenerational plasticity in plants: case studies, mechanisms, and implications for natural populations," Frontiers in Plant Science, vol. 2, pp. $1-10,2011$.

[21] J. J. Herman, S. E. Sultan, T. Horgan-Kobelski, and C. Riggs, "Adaptive transgenerational plasticity in an annual plant: grandparental and parental drought stress enhance performance of seedlings in dry soil," Integrative and Comparative Biology, vol. 52, pp. 77-88, 2012.

[22] I. Yakovlev, C. G. Fossdal, T. Skrøppa, J. E. Olsen, A. H. Jahren, and $\varnothing$. Johnsen, "An adaptive epigenetic memory in conifers with important implications for seed production," Seed Science Research, vol. 22, pp. 63-76, 2012.

[23] M. F. Willson, "Dispersal mode, seed shadows, and colonization patterns," Vegetatio, vol. 107, no. 1, pp. 261-280, 1993.

[24] V. González-Rodríguez, R. Villar, and R. M. Navarro-Cerrillo, "Maternal influences on seed mass effect and initial seedling growth in four Quercus species," Acta Oecologica, vol. 37, no. 1, pp. 1-9, 2011.

[25] M. Vivas, R. Zas, L. Sampedro, and A. Solla, "Environmental maternal effects mediate the resistance of Maritime pine to biotic stress," PloS ONE, vol. 8, Article ID e70148, 2013.

[26] L. M. Holeski, M. S. Zinkgraf, J. J. Couture, T. G. Whitham, and R. L. Lindroth, "Transgenerational effects of herbivory in a group of long-lived tree species: maternal damage reduces offspring allocation to resistance traits, but not growth," Journal of Ecology, vol. 101, pp. 1062-1073, 2013.

[27] K. Donohue, "Completing the cycle: maternal effects as the missing link in plant life histories," Philosophical Transactions of the Royal Society B: Biological Sciences, vol. 364, no. 1520, pp. 1059-1074, 2009.

[28] J. Zhu, T. Matsuzaki, and Y. Gonda, "Wind profiles in a coastal forest of Japanese black pine (Pinus thunbergii Parl.) with different thinning intensities," Journal of Forest Research, vol. 6, no. 4, pp. 287-296, 2001.

[29] T. Taniguchi, S. Tamai, N. Yamanaka, and K. Futai, "Inhibition of the regeneration of Japanese black pine (Pinus thunbergii) by black locust (Robinia pseudoacacia) in coastal sand dunes," Journal of Forest Research, vol. 12, no. 5, pp. 350-357, 2007.

[30] J. Zhu, Y. Gonda, L. Yu, F. Li, Q. Yan, and Y. Sun, "Regeneration of a coastal pine (Pinus thunbergii Parl.) forest 11 years after thinning, Niigata, Japan," PloS ONE, vol. 7, Article ID e47593, 2012.

[31] J. Zhu, T. Matsuzaki, F. Lee, and Y. Gonda, "Effect of gap size created by thinning on seedling emergency, survival and establishment in a coastal pine forest," Forest Ecology and Management, vol. 182, pp. 339-354, 2003.

[32] J. Zhu, F. Li, T. Matsuzaki, Y. Gonda, and M. Yamamoto, "Effects of thinning on wind damage in Pinus thunbergii plantation," Journal of Forestry Research, vol. 14, pp. 1-8, 2003.

[33] B. Adili, M. H. E. Aouni, and P. Balandier, "Unravelling the influence of light, litter and understorey vegetation on Pinus pinea natural regeneration," Forestry, vol. 86, pp. 297-304, 2013.

[34] M. J. Grainger and R. J. Van Aarde, "Is succession-based management of coastal dune forest restoration valid?" Ecological Restoration, vol. 30, pp. 200-208, 2012.

[35] M. J. Grainger and R. J. van Aarde, "The role of canopy gaps in the regeneration of coastal dune forest," African Journal of Ecology, vol. 51, pp. 11-20, 2013.

[36] S. A. Raccuia, V. Cavallaro, and M. G. Melilli, "Intraspecific variability in Cynara cardunculus L. var. sylvestris Lam. Sicilian populations: seed germination under salt and moisture stresses," Journal of Arid Environments, vol. 56, no. 1, pp. 107116, 2004.

[37] W. Derek and A. Groot, "Microclimate of clear-cut, forest interior, and small openings in trembling aspen forest," Agricultural and Forest Meteorology, vol. 87, pp. 313-329, 1997.

[38] F. Valladares, A. Saldaña, and E. Gianoli, "Costs versus risks: architectural changes with changing light quantity and quality in saplings of temperate rainforest trees of different shade tolerance," Austral Ecology, vol. 37, no. 1, pp. 35-43, 2012.

[39] H. Poorter, K. J. Niklas, P. B. Reich, J. Oleksyn, P. Poot, and L. Mommer, "Biomass allocation to leaves, stems and roots: metaanalyses of interspecific variation and environmental control," New Phytologist, vol. 193, no. 1, pp. 30-50, 2012.

[40] D. Harris and A. J. Davy, "Seedling growth in Elymus farctus after episodes of burial with sand," Annals of Botany, vol. 60, no. 5, pp. 587-593, 1987. 
[41] D. Harris and A. J. Davy, "Carbon and nutrient allocation in Elymus farctus seedlings after burial with sand," Annals of Botany, vol. 61, no. 2, pp. 147-157, 1988.

[42] E. J. Edwards, D. G. Benham, L. A. Marland, and A. H. Fitter, "Root production is determined by radiation flux in a temperate grassland community," Global Change Biology, vol. 10, no. 2, pp. 209-227, 2004.

[43] B. S. Phdersen, "The role of stress in the mortality of Midwestern oaks as indicated by growth prior to death," Ecology, vol. 79, no. 1, pp. 79-93, 1998.

[44] Z. Zhang, P. Mao, Y. Liu, Q. Li, S. Liu, and Q. Xue, "Effects of forest structure on natural regeneration of Pinus thunbergii coastal shelter forest in Yantai region," Acta Ecologica Sinica, vol. 30, no. 8, pp. 2205-2211, 2010, (Chinese with English abstract).

[45] T. Toledo-Aceves and M. D. Swaine, "Above- and below-ground competition between the liana Acacia kamerunensis and tree seedlings in contrasting light environments," Plant Ecology, vol. 196, no. 2, pp. 233-244, 2008.

[46] P. Huante and E. Rincón, "Responses to light changes in tropical deciduous woody seedlings with contrasting growth rates," Oecologia, vol. 113, no. 1, pp. 53-66, 1998.

[47] M. B. Walters and P. B. Reich, "Low-light carbon balance and shade tolerance in the seedlings of woody plants: do winter deciduous and broad-leaved evergreen species differ?" New Phytologist, vol. 143, no. 1, pp. 143-154, 1999. 

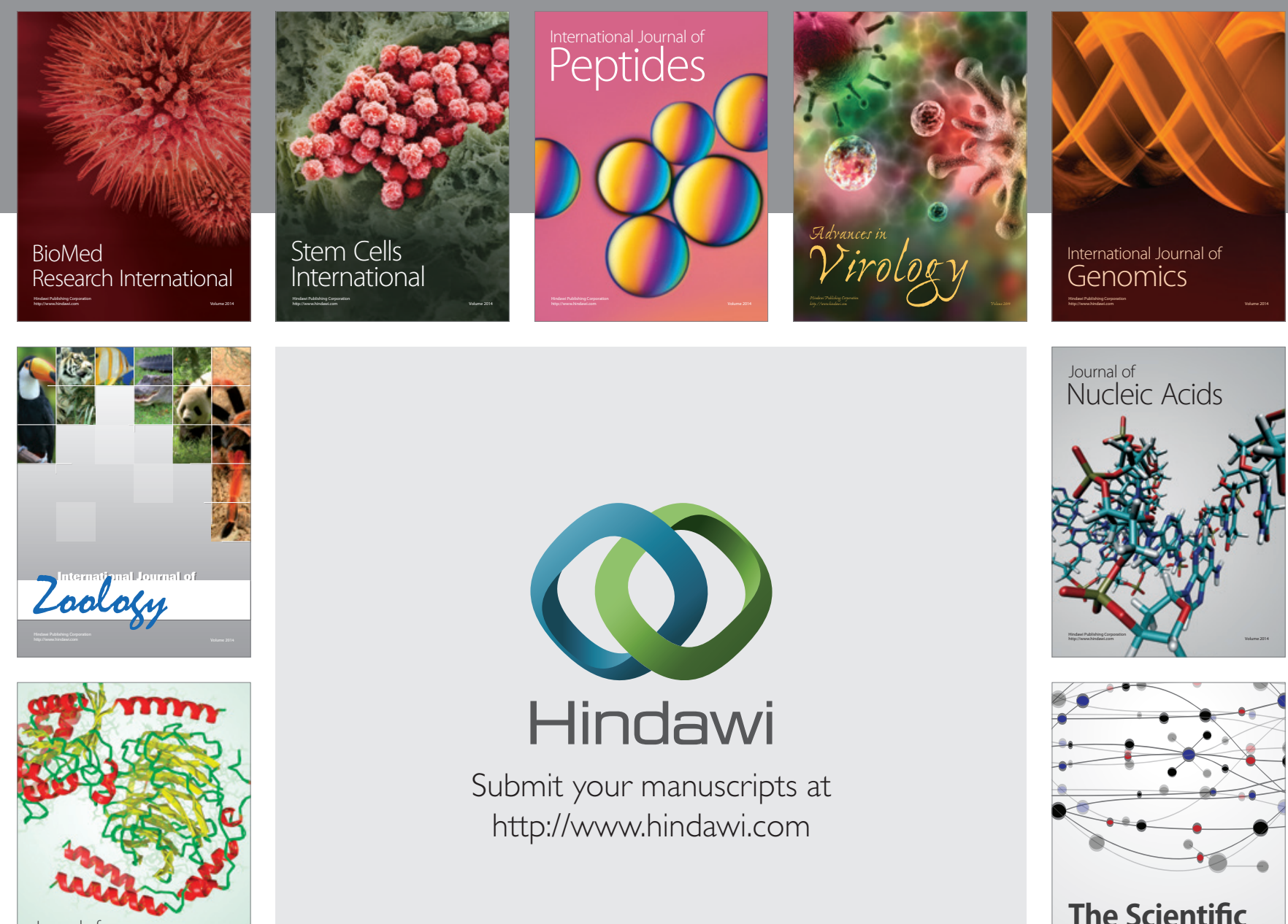

Submit your manuscripts at

http://www.hindawi.com

Journal of
Signal Transduction
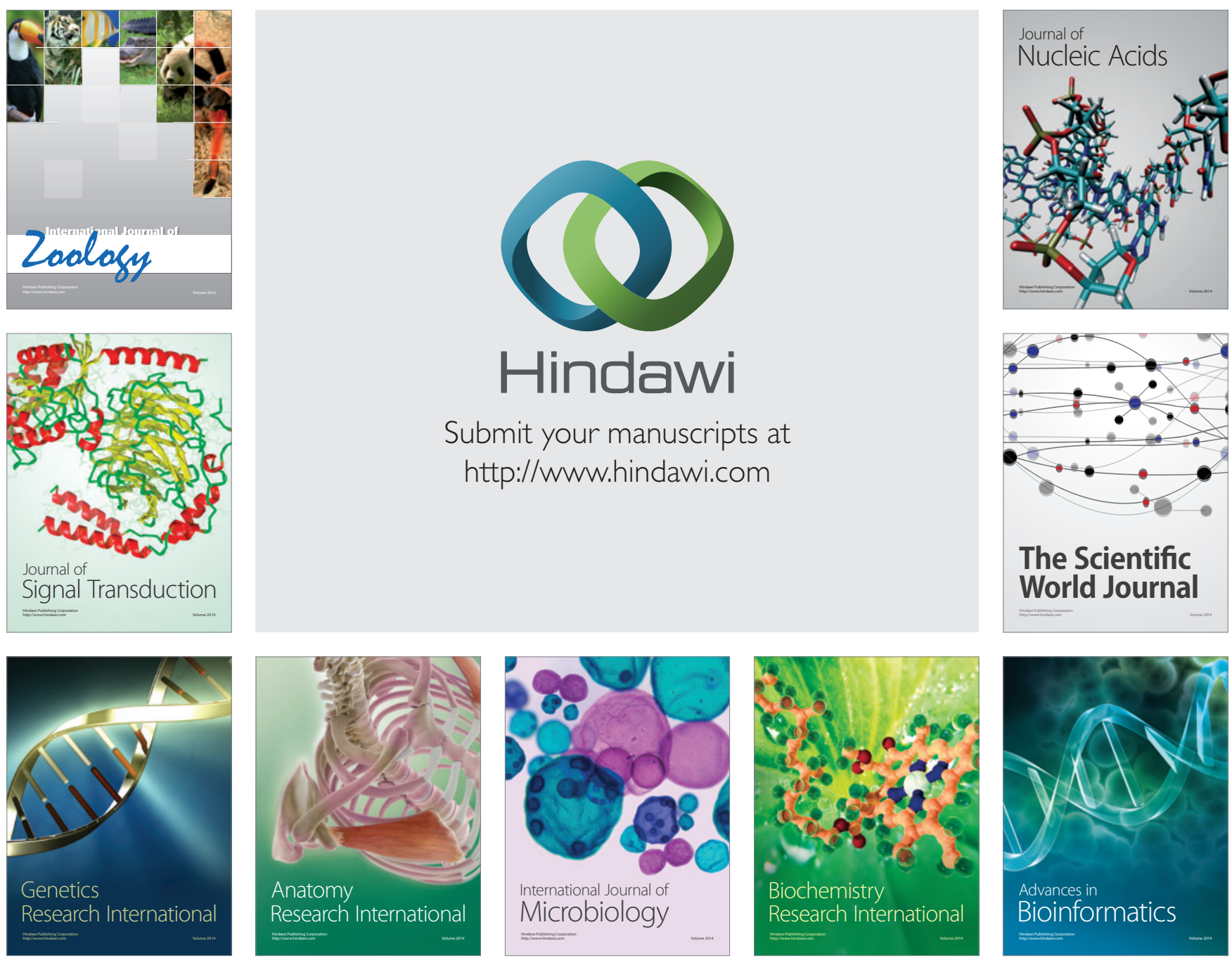

The Scientific World Journal
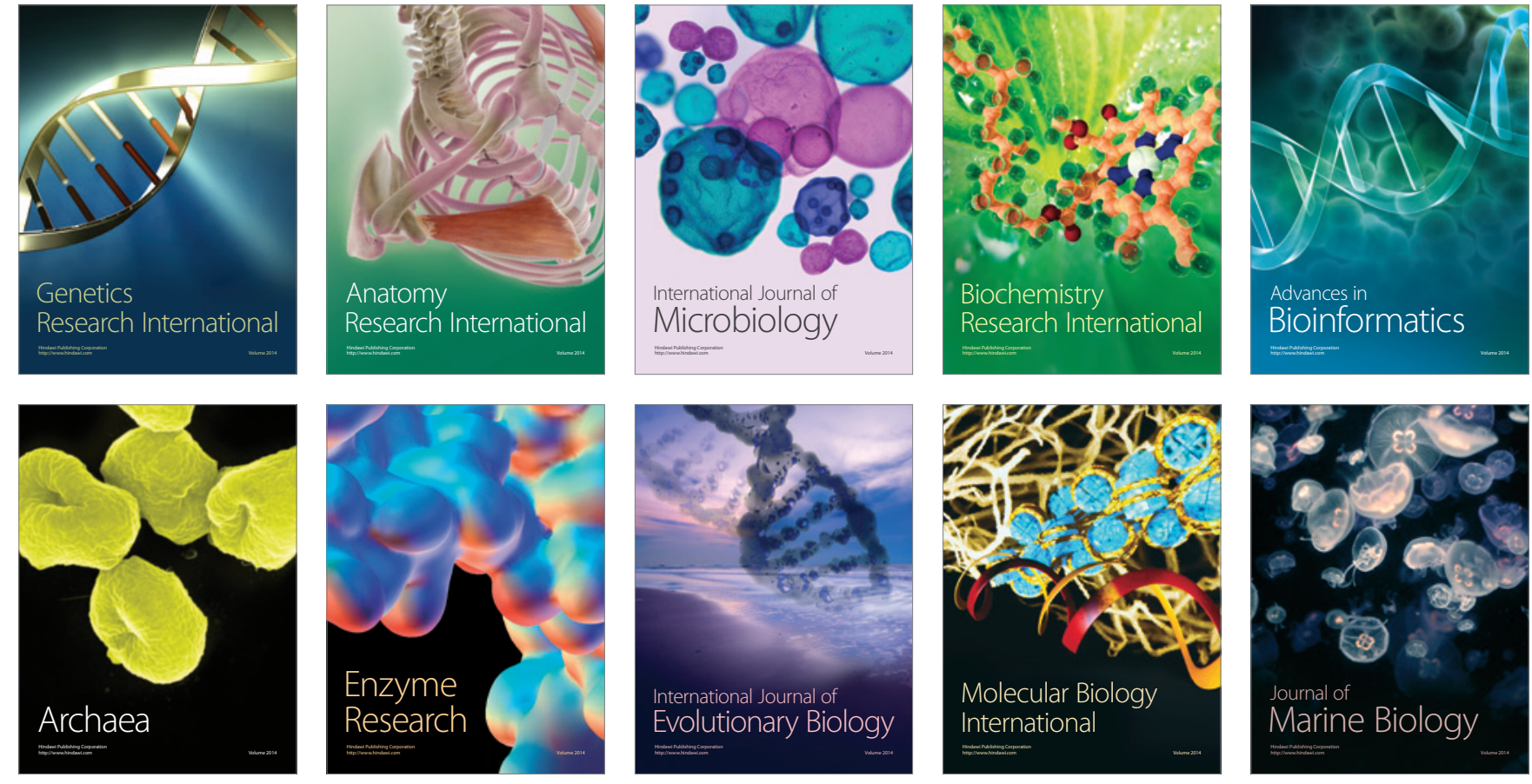